\title{
A TEORIA INTERPRETATIVA DE DWORKIN: UM MODELO CONSTRUTIVO
}

\section{THEORY OF INTERPRETATION DWORKIN: A CONSTRUCTIVE MODEL}

RESUMO:

O presente artigo buscar analisar o processo interpretativo do autor Ronald Dworkin, de maneira a esclarecer a proposta deste autor para um método de interpretação legal que possa oferecer uma adequação justa e legítima das leis e valores comunitários em uma decisão judicial. Dworkin oferece uma teoria de interpretação construtiva que usa o direito como integridade para uma melhor justificativa e legitimação da atividade judiciária, onde o papel do julgador vai além do de simples aplicador de normas. O método utilizado para a realização da pesquisa foi o indutivo, por meio de revisão bibliográfica das obras do referido autor, bem como a leitura de trabalhos elaborados por críticos da teoria de Dworkin.

Palavras-Chave: Interpretação. Integridade. Coerência.

\section{ABSTRACT:}

This article aims to analyze the interpretative process of the author Ronald Dworkin, in order to clarify his proposal for a method of legal interpretation that may offer a fair and legitimate use of the Law and the community values in a judicial decision. Dworkin offers a theory of constructive interpretation that uses Law as integrity for a better justification and legitimation of the judicial activity, where the role of the judge is more than a simple Law applicator. The method used to conduct this study was inductive, through literature review of the works of Dworkin, as well as study of the papers written by the critics of Dworkin's theory.

Key-Words: Interpretation. Integrity. Coherence.

\section{INTRODUÇÃO}

O presente artigo tem como objeto a análise do pensamento do autor norte americano Ronald Dworkin para determinar como esse autor concebe o processo interpretativo do direito e sua aplicação nas decisões judiciais, de maneira que o sistema judiciário possa oferecer uma resposta justa e legítima às lides, utilizando em sua melhor luz as leis e os princípios que permeiam uma comunidade de direito. 
O sistema jurídico brasileiro é de inegável tradição romano-germânica, de direito escrito, fortemente influenciado pelo positivismo de Kelsen, tendo como centro do sistema de direito a norma jurídica positivada. A lei escrita é a fonte primal de Direito e o ideal jurídico se alcança na correspondência plena entre os direitos e as normas.

Embora o sistema brasileiro ainda trate como marco principal a norma escrita, as evoluções sociais, políticas e morais no panorama jurídico brasileiro levaram à necessidade de um maior poder de interpretação dos juízes, de modo que a decisão tomada esteja em conformidade com a realidade de cada lide, permitindo então ao julgador tutelar plenamente o direito em questão. O sistema positivista não é, então, mais hábil a atender à demanda jurídica, o que leva o modelo tradicional de interpretação do direito a ser insuficiente.

Portanto a partir da Constituição de 1988 houve uma abertura principiológica do direito brasileiro, numa busca de dar um fundamento ético e legitimador à nova ordem constitucional brasileira, considerando-a uma estrutura normativa que incorpora os princípios e valores de uma comunidade histórica. A abertura para o uso de valores provoca decisões inovadoras por parte das cortes de justiça, mas também compromete a coerência e a previsibilidade do sistema jurídico. Enquanto o texto constitucional determina a efetivação dos princípios como direitos fundamentais, a jurisprudência e a dogmática jurídica mostramse confusas ao tratar os direitos fundamentais como bens, que podem ser ponderados de acordo com a sua conveniência (CHUEIRI, 2009, p. 46).

Observa-se uma atitude claramente interventiva do Estado na busca da proteção dos direitos sociais, o que leva a uma situação na qual não há praticamente nenhum assunto pertinente ao convívio social no qual o Poder Judiciário não possa vir a emitir juízos. A natureza diversa de muitos dos conflitos que a regulação jurídica do Estado impõe acarreta uma mudança no peso e no valor das decisões judiciais, cujos efeitos podem alcançar não apenas as partes diretamente envolvidas no processo, mas toda uma parcela da sociedade.

Com isso, questiona-se amplamente a legitimidade das decisões proferidas pelos tribunais superiores em casos de difíceis resoluções, bem como os limites da atividade do Poder Judiciário em relação às demandas sociais. Consequentemente, o Poder Judiciário enfrenta uma crise causada, entre outros motivos, pelo questionamento quanto ao papel deste na criação dos direitos no Estado. Ao interpretar uma norma criada pelo Legislador, a atividade jurídica pode levar, inegavelmente, a criações de direitos e os limites dessa atividade criativa estão no núcleo das discussões a respeito do papel do poder judiciário. 
Portanto, para o desenvolvimento desta pesquisa de maneira a analisar o posicionamento de Dworkin e as soluções que este autor oferece em relação a esses problemas enfrentados pelo Poder Judiciário, foram levantados os seguintes problemas:

a) Qual a proposta de Dworkin para um método de interpretação do direito que atenda os ideais de justiça e ofereça legitimidade à atividade judicial?

b) De que maneira Dworkin pretende aliar os princípios, a moral, os costumes e as normas legais nas decisões judiciais?

c) Como Dworkin se posiciona quanto à previsibilidade das decisões e a segurança jurídica?

Ronald Dworkin propõe uma teoria de interpretação do direito que oferece respostas a essas indagações. Uma teoria que expõe um método de aplicação dos princípios e valores mais fundamentais na decisão jurídica, de maneira a legitimar a atividade do Poder Judiciário e alcançar a satisfação do anseio comunitário por justiça e igualdade de tratamento.

Esse processo metodológico defendido por Ronald Dworkin é o foco deste trabalho, onde o objetivo é procurar esclarecer alguns desses problemas teóricos de alta relevância prática, como o processo interpretativo que melhor possa adequar as normas jurídicas com os valores comunitários e as necessidades sociais, bem como os limites do Poder Judiciário no processo de interpretação jurisdicional, através de uma investigação e análise do pensamento de um autor polêmico que vem sendo profusamente utilizado na doutrina jurídica brasileira nos últimos anos.

\section{CRÍTICA AO POSITIVISMO}

Como crítico do positivismo, Dworkin desperta discussões acerca do que é o Direito, obrigação jurídica, proposições conceituais de direito, levantando a questão dos princípios, da moral e da justiça na atividade jurídica. O posicionamento positivista, principalmente aquele transmitido por Austin e seus seguidores, é o de encarar o direito como um produto acabado e que o cientista do direito tem como objetivo apenas o de descrever esse direito, a ciência jurídica deve ser neutra e, portanto, independente de juízos morais e interesses políticos (CALSAMIGLIA, 2001, p. 155). Dworkin põe em questão esse paradigma criticando o posicionamento descritivo dessa teoria jurídica, defendendo uma teoria completa do direito que tenha um aspecto justificador das decisões judiciais. 
O positivismo, buscando uma teoria que possa dar conta da noção de direito e obrigação jurídica, se apóia numa teoria geral que tem em seu esqueleto os seguintes dogmas centrais e organizadores que Dworkin dispõe da seguinte maneira: (DWORKIN, 2002, p. 27 28)

a) $\mathrm{O}$ direito consiste em um conjunto de regras especiais de que faz uso a comunidade, de forma direta ou indireta, para determinar padrões de conduta e parâmetros para punição de determinados comportamentos. Essas regras podem ser identificadas e distinguidas com o auxílio de critérios específicos, de um teste de pedigree que as diferencia das regras espúrias;

b) Este conjunto de regras é exaustivo, os casos em que não forem claramente cobertos por uma regra de direito vigente, o julgador, através de seu discernimento pessoal, cria uma nova regra ou suplementa uma já existente;

c) A obrigação jurídica consiste na contraprestação de fazer ou não fazer algo, de acordo com o disposto na regra jurídica vigente, cujo descumprimento importa no dever público de punição e reprimenda.

Este é apenas o esqueleto do positivismo. A carne é distribuída diferentemente por diferentes positivistas e alguns chegam mesmo a rearranjar os ossos. As diferentes versões diferem sobretudo na sua descrição do teste fundamental de pedigree que uma regra deve satisfazer para ser considerada uma regra jurídica. (DWORKIN, 2002, p. 29)

Dworkin se propõe a defender uma teoria melhor do que as "construções precedentes vêm oferecendo como resposta à situação da atividade dos juízes quando a ação judicial não pode ser submetida a uma regra de direito clara" (SGARBI, 2006, p. 147). Propõe uma teoria mais completa do direito, onde a atividade do julgador deixa de ser a de um simples aplicador de normas, para ser uma ferramenta na construção do direito.

Segundo ele, o direito nasce de um processo de construção e justificação, opondo-se claramente ao direito "como simples questão de fato" que é a tese defendida pelos positivistas.

De acordo com a concepção do direito "como simples questão de fato", os operadores jurídicos sempre estão de acordo quanto ao que é o direito - o que instituições jurídicas e legislativas estabeleceram no passado - e quando divergem, é por questões de moralidade, fidelidade, ou simplesmente uma divergência verbal, mas nunca sobre qual é o direito, pois este já está previamente estabelecido como um conjunto de regras comum a todos.

Para se responder questões relativas ao direito basta apenas a análise dos registros das decisões institucionais sobre o que este deve ser. Quando os julgadores divergem 
teoricamente sobre o que é direito, estão na verdade divergindo sobre aquilo que o direito deveria ser, uma divergência sobre a natureza do direito é uma divergência empírica, sobre a história das instituições jurídicas. Portanto, as divergências existentes entre as teorias semânticas do Direito (as teorias positivistas) referem-se tão somente sobre quais critérios advogados e juízes de fato compartilham e sobre os fundamentos que esses critérios na verdade estipulam.

Mas para Dworkin, os processos judiciais sempre suscitam questões de fato, de direito e as questões interligadas de moralidade, política e fidelidade (DWORKIN, 2003, p. 5). A primeira questão é bastante direta, se os juízes divergem quanto aos fatos concretos, sabemos do que estão divergindo e que uma evidência decidiria a questão. A terceira questão é comum e trata dos conceitos pessoais de certo e errado, o que não apresenta um grande problema. Mas quanto à segunda, a divergência se torna mais complicada por dizer respeito quanto à definição de qual é o direito aplicável e o que ele estabelece.

Advogados e juízes parecem freqüentemente divergir sobre questões de direito, sobre a verdade de uma proposição jurídica e os fundamentos desse direito. Essa divergência sobre o que determinada lei realmente é, sobre os fundamentos do direito, Dworkin nomeia de “divergência teórica do direito". (DWORKIN, 2003, p. 8)

\begin{abstract}
A divergência empírica sobre o direito quase nada tem de misteriosa. As pessoas podem divergir a propósito de quais palavras estão nos códigos da mesma maneira que divergem sobre quaisquer outras questões de fato. Mas a divergência teórica no direito, a divergência quanto aos fundamentos do direito, é mais problemática. [...] Advogados e juízes têm, de fato, divergências teóricas. Divergem, por exemplo, sobre o que o direito realmente é, sobre a questão da segregação racial ou dos acidentes de trabalho, mesmo quando estão de acordo sobre as leis que foram aplicadas, e sobre o que as autoridades públicas disseram e pensaram no passado. (DWORKIN, 2003, p. 8)
\end{abstract}

Para Dworkin, a maioria das teorias de direito recentes têm tentado dar uma solução ao problema dos desacordos teóricos partindo da premissa de que juízes e advogados utilizam fundamentalmente os mesmos critérios para decidir quando uma proposição jurídica é verdadeira ou falsa. Insistem que esses utilizam critérios lingüísticos para avaliar as proposições jurídicas e estão sempre de acordo quanto ao que é o direito. (DWORKIN, 2003, p. 40-41)

Dworkin chama esse argumento de "aguilhão semântico", que é o defeito de se tentar entender o direito apenas como uma questão de discordância de convenção social, é uma imagem equivocada do que devem ser as divergências. Suas vítimas pensam que apenas podemos discutir sensatamente se seguirmos os mesmos critérios, mesmo que estes não sejam 
exatos (DWORKIN, 2003, p. 55-56). Os filósofos do direito tentam localizar as regras fundamentais que devem estar contidas, mas não reconhecidas na prática jurídica, produzindo e discutindo as teorias semânticas do direito. ${ }^{1}$ (VIDAL, 1999b, p. 259)

Para Dworkin, o tipo de divergência alegada pelos filósofos de direito não corresponde ao tipo de divergência que juízes e advogados realmente têm. Afirma que pode ser coerente quando estes divergem quanto a um fato histórico ou social, mas a maioria de divergências em direito é teórica e não empírica.

Conforme este autor, o direito não pode ser tratado como um simples dado objetivo, visto que tal foco não permite entender os conflitos interpretativos, e também, que o direito não é apenas uma questão semântica, mas sim de concepção. Sustenta que os filósofos de direito tentam subestimar a divergência teórica por meio de explicações, como a que:

\begin{abstract}
Os advogados e juízes apenas fingem, ou que só divergem porque o caso que têm em mãos se situa numa zona cinzenta ou periférica das regras comuns. Em ambos os casos (dizem eles), o melhor a fazer é ignorar os termos usados pelos juízes e tratálos como se divergissem quanto à fidelidade ou reforma do direito, e não quanto ao direito. Aí está o aguilhão: estamos marcados como seu alvo por uma imagem demasiado tosca do que deve ser a divergência. (DWORKIN, 2003, p. 56)
\end{abstract}

Porém, Dworkin argumenta que a possibilidade de que toda a divergência teórica em direito seja fruto de fingimento não pode ao menos considerada. Assim, o autor chega à conclusão de que é impossível determinar o que é ou não direito por meio de critérios semânticos. A única maneira de oferecer uma explicação satisfatória dos desacordos teóricos e extrair o "aguilhão semântico" é "abandonar as teorias semânticas e optar por uma perspectiva de análise do Direito diferente: uma teoria que considere o Direito como um conceito interpretativo".2 (VIDAL, 1999b, p. 262, tradução nossa)

Dworkin faz referência à Hart quando trata das teorias semânticas de direito, que segundo Dworkin é caracterizada por adotar o ponto de vista segundo o qual são os fatos que determinam os elementos do direito, para que algo seja qualificado como direito deve necessariamente corresponder a certos fatos históricos. (VIDAL, 1999b, p. 260)

A respeito deste tema, Hart, em seu pós-escrito, rebate os argumentos de Dworkin afirmando que, apesar de seus critérios de validade jurídica basearem-se fundamentalmente naquilo que Dworkin chama de pedigree, Hart admite que princípios de justiça e valores morais podem integrar o conteúdo jurídico. Portanto, ao imputar-lhe o positivismo como uma questão meramente factual: 
nem é minha qualquer forma de positivismo meramente factual. (HART, 2005, p. 309)

Assim, Hart sustenta que, ao contrário do que Dworkin pensa, além de sua teoria não ser meramente factual, posto que admite o ingresso de valores morais, sua teoria não tem como cerne a justificação da coerção. Hart afirma que não há nada em sua teoria que apóie o ponto de vista segundo o qual o direito consiste em justificar o uso da coerção:

De fato, penso que é totalmente despiciendo procurar qualquer finalidade mais específica que o direito, enquanto tal, sirva, para além de fornecer orientações à conduta humana e padrões de crítica de tal conduta. (HART, 2005, p. 310)

Assim, Hart nega que sua teoria do Direito seja a teoria positivista meramente factual apresentada por Dworkin em O Império do Direito, e conseqüentemente nega a presença da doutrina semântica em sua obra.

Mas Hart, ao sustentar que não se preocupa com a justificativa da coerção, reafirma o traço característico positivista, que Dworkin gosta de nomear como "direito como simples questão de fato". Ainda, Dworkin atribui às teorias semânticas a preocupação em extrair regras comuns de um criterioso estudo da atividade dos advogados e juízes, atividade esta empreendida por Hart em suas obras.

Dworkin propõe que o direito é um conceito interpretativo e que os textos por si só não possuem significados por si mesmos. É necessário um enfoque determinado, que os positivistas não têm apreciado. O seu conceito interpretativo do direito é a arma mais poderosa de Dworkin no desafio ao positivismo (CALSAMIGLIA, 1992, p. 160), como veremos a seguir.

\section{ETAPAS INTERPRETATIVAS}

De modo a refinar a interpretação construtiva, transformando-a em um instrumento apropriado ao estudo do direito enquanto prática social, Dworkin faz uma separação analítica em três etapas interpretativas: a etapa "pré-interpretativa", que trata do problema da identificação do direito; a etapa "interpretativa" que busca um significado, uma justificação para o direito; e a etapa "pós-interpretativa", que busca a melhor interpretação, o melhor ajuste de acordo com o que a prática requer. (DWORKIN, 2003, p. 81) 
Na etapa pré-interpretativa é realizada a identificação e qualificação do objeto a ser interpretado, identifica as regras e normas que proporcionam o conteúdo da prática. Embora seja qualificada como "pré-interpretativa”, Dworkin alerta que mesmo nessa fase é necessário algum tipo de interpretação. As regras sociais não possuem um rótulo de identificação, mas para o sucesso deste processo interpretativo é necessário um alto grau de consenso na identificação, "de maneira que a presença deste consenso se converta para Dworkin praticamente em um elemento definidor das comunidades interpretativas". ${ }^{3}$ (VIDAL, 1999b, p. 274-275, tradução nossa)

$\mathrm{Na}$ etapa interpretativa o intérprete vai se concentrar numa justificativa geral para os elementos da prática identificada na etapa anterior. É nessa etapa que o intérprete vai buscar uma justificativa de valores e objetivos que se considera que a prática persegue.

\footnotetext{
A justificativa não precisa ajustar-se a todos os aspectos ou características da prática estabelecida, mas deve ajustar-se o suficiente para que o intérprete possa ver-se como alguém que interpreta essa prática, não como alguém que inventa uma nova prática. (DWORKIN, 2003, p. 81)
}

Por último há a etapa "pós-interpretativa" onde o objetivo é ajustar a idéia do que a prática requer para melhor servir à justificativa da etapa interpretativa. Trata-se de determinar o que a prática realmente necessita para conseguir uma máxima realização dos princípios que se considera que justificam.

Nesta terceira fase interferem valores de convicção, pretende-se alcançar uma aplicação coerente da melhor justificativa prática, essa fase pretende estruturar a prática à luz de seus objetivos, o que pode implicar no "abandono, reforma ou introdução de alguma das regras identificadas na primeira etapa; isto coincide precisamente com o requisito do segundo elemento da atitude interpretativa". ${ }^{4}$ (VIDAL, 1999b, p. 275, tradução nossa)

São os juízos morais que vão ser utilizados para oferecer a melhor interpretação da prática social, assim como os juízos estéticos são utilizados para julgar as obras de arte.

Uma das teses principais da teoria de Dworkin consiste em sustentar que sempre haverá uma interpretação que mostre o objeto como o melhor caso possível do gênero que se considera que pertença. Na etapa pós-interpretativa, os juízos valorativos são desenvolvidos ao máximo, de forma que passe a ser a melhor prática possível dentre as distintas interpretações que admitam os elementos identificados e interpretados nas etapas anteriores. É nesta etapa que se estabelece uma relação entre direito e moral. (VIDAL, 1999a, p. 44)

Para Dworkin, o direito é um processo abstrato e como tal, deve ser uma teoria geral do direito: 
Sua finalidade é interpretar o ponto essencial e a estrutura da jurisdição, não uma parte ou seção específica desta última. Contudo, apesar de sua abstração, trata-se de interpretações construtivas: tentam apresentar o conjunto da jurisdição em sua melhor luz, para alcançar o equilíbrio entre a jurisdição tal como a encontram e a melhor justificativa dessa prática. (DWORKIN, 2003, p. 112)

O referido autor trata uma decisão judicial como uma "peça de filosofia do direito" (DWORKIN, 2003, p. 113) onde o Juiz age interpretando todos os princípios morais e legais de uma comunidade, trazendo-os para o caso concreto e fazendo a devida interpretação construtiva, dando à lei a melhor interpretação possível dentro do caso concreto, sob o prisma político da situação presente, aliado a uma crítica análise dos precedentes.

Porém Vidal (1999b) faz a crítica de que Dworkin, ao sustentar que a interpretação construtiva leva a uma única e melhor interpretação da prática social, não considera que o Direito, como um fenômeno complexo, muitas vezes serve a vários valores e, assim, não apenas uma, mas várias outras interpretações que fariam prevalecer um certo valor frente a outro poderiam ser admitidas. Assim não se poderia dizer que uma, e apenas uma dessas interpretações, seria a correta. (VIDAL, 1999b, p. 291)

Mas Dworkin afasta esta possibilidade, sustenta que é sempre possível encontrar uma interpretação que seja a melhor, a única resposta correta para o caso concreto. Mas para que isso ocorra, é necessário que se recorra a juízos morais, que é precisamente a atividade realizada na etapa pós-interpretativa.

Deste modo, conforme Vidal:

O juiz dworkiniano deve se situar precisamente na etapa pós-interpretativa e sua tarefa consiste em resolver os casos concretos através da elaboração da melhor teoria que reconstrua todo o sistema jurídico. É neste sentido em que pode dizer-se que Dworkin adota uma visão holística ou integradora a respeito do fenômeno jurídico. ${ }^{5}$ (VIDAL, 1999a, p. 44, tradução nossa)

Ainda, a referida autora critica Dworkin no sentido de que apesar de este sustentar que para chegar à etapa pós-interpretativa é necessária uma identificação, um consenso a respeito da matéria jurídica na etapa pré-interpretativa, Dworkin descuida desse aspecto fundamental para a teoria do Direito: uma teoria das fontes do ordenamento jurídico. (VIDAL, 1999b, p. 331-332)

É a partir dessas fontes que se reconstrói toda a ordem jurídica, mas Dworkin parece menosprezar a matéria de critérios de identificação dos elementos jurídicos, embora estes sejam essenciais para determinar quais são os padrões que os juízes têm o dever de aplicar e que, segundo sua própria definição, conformam o conteúdo do direito. Além disso, Dworkin é 
um ferrenho opositor à regra de reconhecimento de Hart, mas não oferece nenhuma teoria das fontes de direito que satisfaça essa matéria.

Porém,

[...] a teoria de Dworkin acrescenta algo que não parece estar nas teorias como a de Hart e que pode contribuir para a melhor compreensão do fenômeno jurídico: a idéia de 'coerência', que é o que permitirá ver o Direito objetivo não como um mero conjunto de normas, mas sim como um conjunto de normas 'orientadas', a dizer, com certos objetivos. Este elemento parece inclusive necessário para dar conta das funções que o próprio Hart atribui ao Direito como guia de conduta de uma determinada sociedade. ${ }^{6}$ (VIDAL, 1999b, p. 332, tradução nossa)

A referida autora defende que no âmbito jurídico, as decisões adotadas por qualquer instância devem apresentar-se como justificadas juridicamente e, para isso, exige que estejam de acordo com o Direito como um todo unitário (e não como um mero agregado de distintos materiais jurídicos). Para tanto, em sua opinião, se exige levar a cabo o tipo de atividade interpretativa construtiva de todos os materiais jurídicos, a qual Dworkin sustenta em sua obra. (VIDAL, 1999a, p. 46) O modelo construtivo seria, segundo a autora, o candidato plausível para ser o critério de êxito de todas as formas de interpretação.

A chave para a compreensão da argumentação jurídica de Dworkin reside na sua interpretação construtiva. Na opinião de Vera Karam de Chueiri:

\begin{abstract}
A sofisticação de Dworkin está no fato de que a chave para a compreensão da sua proposta de uma filosofia liberal do direito está na compreensão da argumentação jurídica enquanto exercício de interpretação construtiva, no qual o direito consiste na melhor justificação das práticas jurídicas como um todo, na história narrativa que faz dessas práticas o melhor possível. (CHUEIRI, 1995, p. 65)
\end{abstract}

A interpretação construtiva demonstra ser capaz de garantir, simultaneamente, uma solução justa para um determinado caso e rejeitar a discricionariedade, onde a centralidade dos direitos fundamentais age como condição possibilitadora da democracia. (MARTINS, 2006, p. 278)

\title{
4 DIREITO COMO INTEGRIDADE E A COERÊNCIA NA DECISÃO JUDICIAL
}

Dworkin critica em suas obras as correntes filosófico-jurídicas como o convencionalismo, utilitarismo, pragmatismo e, principalmente, o positivismo. Sustenta que tais correntes são insuficientes pois não oferecem a justificação necessária para o exercício da jurisdição. 
A atividade jurídica deve ser coerente, fiel a princípios como equidade, justiça, legalidade e integridade. É sobre o princípio da integridade que repousa a filosofia de Ronald Dworkin, que utiliza um modelo ideal de sociedade democrática, que considera a comunidade como um agente moral, a qual denomina comunidade de princípios. (DWORKIN, 2003, p. 254)

A respeito desse tema, Stephen Guest esclarece:

\begin{abstract}
A comunidade propriamente dita é aquela em que a associação fraternal fornece a justificação para a obrigação política, enfatiza a preocupação pelo bem-estar e eqüidade. Dworkin chama tal comunidade de 'comunidade de princípios' [...]. A comunidade de princípio, diz ele, faz a responsabilidade de cidadania especial porque cada cidadão deve respeitar os princípios de imparcialidade e justiça que estão inseridos nos acordos políticos de uma comunidade em particular. A comunidade de princípios, portanto, fornece a melhor defesa da legitimidade, bem como, a defesa de nossa própria cultura política. ${ }^{7}$ (GUEST, 1997, p. 70, tradução nossa)
\end{abstract}

$\mathrm{Na}$ comunidade de princípios existe um sentimento coletivo de responsabilidade e comprometimento. Nesta comunidade, os cidadãos encaram as responsabilidades da comunidade como pessoais, desprezam o sentimento egoísta ao resolver um conflito:

[...] promove a união da vida moral e política dos cidadãos: pede ao bom cidadão, ao decidir como tratar seu vizinho quando os interesses de ambos entram em conflito, que interprete a organização comum da justiça à qual estão comprometidos em virtude da cidadania. (DWORKIN, 2003, p. 230)

Ainda,

Uma sociedade política que aceita a integridade como virtude política se transforma, desse modo, em uma forma especial de comunidade, especial num sentido que promove sua autoridade moral para assumir e mobilizar monopólio de força coercitiva. (DWORKIN, 2003, p. 228)

Uma comunidade de princípios se rege pela integridade. Trazem consigo a promessa que de que o direito será escolhido, alterado, desenvolvido e interpretado de um modo global, fundado em princípios. (DWORKIN, 2003, p. 258) Seus membros partilham de responsabilidades que reforça o caráter de culpa e vergonha coletiva quando agem de forma injusta.

O direito como integridade nega o traço convencionalista de direito unicamente como relato de fatos estabelecidos no passado, ou do pragmatismo como programas de estratégia voltados para o futuro. Abarca o direito como uma atividade interpretativa, combina elementos voltados tanto para o passado quanto para o futuro. Interpreta a prática jurídica como uma atividade dinâmica, o direito em processo de desenvolvimento contínuo. Assim, o 
direito como integridade rejeita, por considerar inútil, "a questão de se os juízes descobrem ou inventam o direito; sugere que só entendemos o raciocínio jurídico tendo em vista que os juízes fazem as duas coisas e nenhuma delas." (DWORKIN, 2003, p. 271)

No direito como integridade as proposições jurídicas são verdadeiras se constam ou derivam de princípios de justiça, equidade e devido processo legal adjetivo, os quais oferecem a melhor interpretação construtiva da prática jurídica de uma comunidade. Os juízes são instruídos a identificar direito e deveres legais, partindo do pressuposto de que foram criados por um único autor - a comunidade personificada - expressando uma concepção coerente de justiça e equidade. (DWORKIN, 2003, p. 272)

Mas o direito como integridade não é apenas o produto da interpretação da prática jurídica, mas também sua fonte de inspiração, pede aos juízes que exerçam uma atividade contínua de interpretação do mesmo material que afirmam já terem interpretado com sucesso. (DWORKIN, 2003, p. 273)

Essa característica do direito como integridade expressa a dinamicidade da teoria de direito dworkiniana, que conforme Chueiri:

Esse dinamismo faz com que o direito se recicle constantemente, revigorando sua estrutura ante a atrofia ameaçadora dos esqueletos esclerosados do positivismo e do utilitarismo que lhe oferecem uma frágil, quase inepta sustentação. (CHUEIRI, 1995, p. 130)

Ainda conforme essa autora, o direito como integridade segue a lógica do pensamento moderno, "da qual a razão é a fundadora e cujas unidades constitutivas funcionam, harmonicamente, a interagir uma com a outra" (CHEIRI, 1995, p. 131). Desta forma, esta julga o direito como integridade como a melhor concepção do direito e, ao mesmo tempo, como unidade constitutiva de um projeto de sociedade.

Dworkin pontua que a interpretação criativa busca sua estrutura formal na idéia de intenção, na medida em que pretende impor um propósito à tradição que se está interpretando.

\footnotetext{
Pode o jurista afirmar [...] que o impacto da lei sobre o direito é determinado pela pergunta de qual a interpretação, entre as diferentes possibilidades admitidas pelo significado abstrato do termo, promove melhor o conjunto de princípios e políticas que oferecem a melhor justificativa política para a lei na época em que foi votada. (DWORKIN, 2005, p. 190)
}

O autor então faz uma comparação do Direito com a atividade literária, argumentando que em uma interpretação legal, os juízes agem como autores e críticos. 
Para ilustrar melhor esse processo de interpretação legal, Dworkin utiliza hipoteticamente a figura do "romance em cadeia" que seria um projeto no qual um grupo de romancistas escreveria um romance em série, no qual cada romancista interpreta os capítulos que recebeu para, a partir desse, escrever um novo capítulo, que então é analisado pelo romancista seguinte e adicionado de um novo capítulo, e assim por diante.

A atividade do intérprete do romance pode ser comparada à do intérprete de uma lei num caso difícil. Um grupo de romancistas deve escrever uma novela, onde cada autor escreve um trecho, e a atividade do último novelista é sempre a de interpretar os argumentos dos antecessores e conforme suas próprias convicções escrever a continuidade do texto, de forma coerente, com consistência narrativa. "A complexidade dessa tarefa reproduz a complexidade de decidir um caso difícil de direito como integridade.” (DWORKIN, 2003, p. 276)

Comparada à atividade jurídica, o juiz ao analisar o caso difícil também deve dar uma continuidade coerente à história da comunidade, ser criterioso e estar ciente do seu papel único no romance, agir de forma que justifique os rumos que irá dar na história do romance.

Assim como um autor no romance em cadeia, cada juiz deve:

Ler tudo o que outros juízes escreveram no passado, não apenas para descobrir o que disseram, ou seu estado de espírito quando o disseram, mas para chegar a uma opinião sobre o que esses juízes fizeram coletivamente, da maneira como cada um de nossos romancistas formou uma opinião sobre o romance coletivo escrito até então. (DWORKIN, 2005, p. 238)

Ao decidir um novo caso, o juiz deve considerar-se como parceiro de um complexo empreendimento em cadeia, do qual um imenso número de decisões, estruturas, convenções e práticas formam sua história; e ao juiz cabe dar uma continuidade coerente a essa história no futuro, consciente de que deve interpretar o que aconteceu antes e levar adiante a incumbência que tem em mãos, e não partir em alguma nova direção. (DWORKIN, 2005, p. 238)

Conforme Vianna (1999), Dworkin tem em sua tese uma concepção de revolução permanente, onde o direito é uma atividade de progressão contínua tendo em vista a realização dos princípios de liberdade e igualdade.

O roman à chaîne como um processo ininterrompido da criação do direito reclama uma interpretação construtivista em que cada juiz, para chegar a uma decisão, especialmente quando mobilizado pelo julgamento dos hard cases, deve ter como ponto de partida uma teoria que satisfaça a condição de se apresentar como uma reconstrução racional da ordem jurídica de que ele faz parte. (VIANNA, 1999, p. 36) 
Para que o romance em cadeia tenha coerência, é necessário que haja respeito aos capítulos anteriores e uma devida justificação para a elaboração do capítulo seguinte. Não significa propriamente que a história deve seguir uma direção rígida iniciada pelo primeiro romancista, isso seria contrariar o caráter dinâmico da interpretação construtiva, mas sim que cada capítulo escrito tenha coerência com os anteriores e demonstre uma justificativa plausível para os novos rumos a serem tomados. O aplicador do direito deve estar sempre disposto a abandonar soluções jurídicas adotadas no passado para consagrar novas diretrizes jurídicas. (ARÊAS, 2005, p. 581)

Traçando um paralelo entre o romance em cadeia e a atividade jurisdicional, Dworkin sustenta que:

\begin{abstract}
O direito como integridade [...] pede ao juiz que se considere como um autor na cadeia do direito consuetudinário. Ele sabe que outros juízes decidiram casos que, apesar de não exatamente iguais ao seu, tratam de problemas afins; deve considerar as decisões deles como parte de uma longa história que ele tem de interpretar e continuar, de acordo com suas opiniões sobre o melhor andamento a ser dado à história em questão. (Sem dúvida, para ele a melhor história será a melhor do ponto de vista da moral política, e não da estética.) [...] O veredito do juiz - suas conclusões pós-interpretativas - deve ser extraído de uma interpretação que ao mesmo tempo se adapte aos fatos anteriores e os justifique, até onde isso seja possível. (DWORKIN, 2003, p. 286)
\end{abstract}

Dworkin admite que a interação entre adequação e justificação é complexa, assim como na literatura a interpretação vai ser marcada pelas convicções artísticas e literárias de cada romancista, no direito, a decisão judicial vai ser influenciada pelas convicções políticas e morais do julgador.

$\mathrm{O}$ autor explora mais detalhadamente esse processo interpretativo realizado pelo julgador a partir da alegoria de Hércules, um juiz imaginário que aceita o direito como integridade. Através dos passos de Hércules, Dworkin explora a atividade jurisdicional e aprofunda seus argumentos em defesa de sua tese.

Hércules é um filósofo consciente da complexidade da tarefa da decisão judicial, tem capacidade e tempo ilimitados, conhece a letra da lei e a história de sua comunidade, toma decisões dentro dos critérios de adequação e justificação.

É importante frisar esse traço de juiz-filósofo de Hércules, posto que para Dworkin:

O voto de qualquer juiz é, em si, uma peça de filosofia do direito, mesmo quando a filosofia está oculta e o argumento visível é dominado por citações e listas de fatos. A doutrina é a parte da jurisdição, o prólogo silencioso de qualquer veredito. (DWORKIN, 2003, p. 113) 
Por tal razão sustenta que a parte clássica da filosofia moral e política deve fazer parte da formação dos profissionais de direito, porque os Juízes carecem de informação, controle e legitimidade para concretizar os direitos sociais, econômicos e financeiros. Não bastam apenas conhecimentos da técnica jurídica, mas uma ampla capacidade de raciocínio filosófico que muitos juristas insistem em ignorar.

\begin{abstract}
É perfeitamente compreensível que os juristas temam a contaminação pela filosofia moral, particularmente pelos filósofos que falam sobre direitos, porque as nuanças fantasmagóricas desse conceito assombram o cemitério da razão. [...] Não é necessário que os juristas desempenhem um papel passivo no desenvolvimento de uma teoria dos direitos morais contra o Estado, assim como não foram passivos no desenvolvimento da sociologia e da economia jurídicas. Eles devem reconhecer que o direito não é mais independente da filosofia do que essas outras disciplinas. (DWORKIN, 2002, p. 233-234)
\end{abstract}

Junto com esse juiz-filósofo, o leitor é levado a acompanhar todo o paciente processo de análise de um caso e as possibilidades interpretativas que Hércules considera. Dworkin propõe uma série de questões e demonstra de forma didática como Hércules analisa e decide as questões, usando os princípios, a lei e os fatos reunidos sob o prisma da integridade.

\footnotetext{
Hércules interpreta não só o texto da lei, mas também sua vida, o processo que se inicia antes que ela se transforme em lei e que se estende para muito além desse momento. Quer utilizar o melhor possível esse desenvolvimento contínuo, e por isso sua interpretação muda à medida que a história vai se transformando. (DWORKIN, 2003, p. 416)
}

Dworkin assinala, com o exemplo de Hércules, que o juiz, ao decidir uma lide, deve capturar a "força gravitacional" dos precedentes que atuam nas decisões judiciais, que é sustentada pelos argumentos de princípios. Ainda, que a decisão deve ser como uma "teia inconsútill", ou seja, como uma trama que não apresenta emendas ou costuras, sem fendas e sem interromper o fio argumentativo.

\footnotetext{
Hércules concluirá que sua doutrina da eqüidade oferece a única explicação adequada da prática do precedente em sua totalidade. Extrairá algumas outras conclusões sobre suas próprias responsabilidades quando da decisão de casos difíceis. A mais importante delas determina que ele deve limitar a força gravitacional das decisões anteriores à extensão dos argumentos de princípio necessários para justificar tais decisões. (DWORKIN, 2002, p. 177)
}

Dworkin preza pela coerência na interpretação jurídica, demonstrando por meio de Hércules de que modo essa coerência é atingida. Este, ao julgar uma lide, deve construir um esquema de princípios abstratos e concretos que possam fornecer uma justificação coerente a todos os precedentes do direito costumeiro e, "na medida em que estes devem ser justificados 
por princípios, também um esquema que justifique as disposições constitucionais e legislativas." (DWORKIN, 2002, p. 182)

Dworkin sustenta que, tanto na esfera jurisdicional quanto legislativa, é necessária uma coerência de forma que não se trate os direitos individuais de forma arbitrária, o mandamento de coerência inclui todos os argumentos de princípios, dos quais uma comunidade política obtém a sua legitimidade. "Em caso de qualquer tratamento arbitrário que violar um dos princípios pleiteados por motivos legítimos, a própria legitimidade estará em jogo" (GÜNTHER, 2004, p. 408). Os princípios oferecem os meios argumentativos para se construir o argumento jurídico necessário para que este valha como normativamente justificado.

\section{Conforme Habermas:}

Dworkin exige a construção de uma teoria do direito, não de uma teoria da justiça. A tarefa não consiste na construção filosófica de uma ordem social fundada em princípios da justiça, mas na procura de princípios e determinações de objetivos válidos, a partir dos quais seja possível justificar uma ordem jurídica concreta em seus elementos essenciais, de tal modo que nela se encaixem todas as decisões tomadas em casos singulares, como se fossem componentes coerentes. (HABERMAS, 2003, p. 263)

Hércules deve oferecer uma coerência de justificação vertical e também horizontal. A coerência vertical vai ser expressa pelo respeito à hierarquia das leis, pela autoridade, onde Hércules deve "organizar a justificação de princípio em cada um desses níveis, de tal modo que a justificação seja consistente com os princípios que fornecem a justificação dos níveis mais elevados." (HABERMAS, 2003, p. 183)

A coerência horizontal vai exigir de Hércules que decida de forma a abarcar os juízos de valor, princípios e preceitos dogmáticos de uma comunidade, construindo o argumento jurídico dentro de um contexto de justificação abrangente de todos os direitos relevantes em uma comunidade, justificando a decisão em um nível em que deve ser consistente com a justificação de outras decisões oferecidas neste mesmo nível. (GÜNTHER, 2004, p. 410)

Portanto, para Dworkin não bastam apenas explicações a respeito do rumo das decisões preferidas na comunidade, mas é necessária uma justificação:

Qualquer conjunto de leis e decisões pode ser explicado histórica, psicológica ou sociologicamente, mas a consistência exige uma justificação, e não uma explicação, e a justificação deve ser plausível, e não postiça. Se a justificação que Hércules concebe estabelece distinções que são arbitrárias, e se vale de princípios que não são convincentes, então ela não pode, de modo algum, contar como uma justificação. (DWORKIN, 2002, p. 186) 
Hércules adota o Direito como integridade, vez que está convencido de que este oferece tanto uma melhor adequação quanto uma melhor justificativa da prática jurídica como um todo.

O autor em estudo alerta que as respostas às várias questões que Hércules lida em seus exemplos não supõem que estas definem o direito como integridade como uma concepção geral do direito, são apenas as respostas que lhe parecem as melhores. O direito como integridade consiste numa abordagem, em perguntas mais do que em respostas, e outros julgadores poderiam dar respostas diferentes das de Hércules às perguntas colocadas por essa concepção do direito, mas rejeitar os pontos de vista distintos por considerá-los pobres ou insuficientes enquanto interpretações construtivas da prática jurídica não significa uma rejeição ao direito como integridade, mas sim que o julgador ter-se-á unido a sua causa. (DWORKIN, 2003, p. 287)

$\mathrm{O}$ direito como integridade tem uma atitude mais complexa com relação aos ramos do direito. Seu espírito geral os condena, pois o princípio adjucativo de integridade pede que os juízes tornem a lei coerente como um todo, até onde lhes seja possível fazê-lo, e isso poderia ser mais bem-sucedido se ignorassem os limites acadêmicos e submetessem alguns segmentos do direito a uma reforma radical, tornando-os mais compatíveis em princípio com os outros. "Contudo, o direito como integridade é interpretativo, e a compartimentalização é uma característica da prática jurídica que nenhuma interpretação competente pode ignorar." (DWORKIN, 2003, p. 301)

Hércules responde a esses impulsos antagônicos procurando uma interpretação construtiva da compartimentalização, é um juiz cuidadoso e criterioso, de forma metódica seleciona diversas hipóteses para corresponderem à melhor interpretação dos casos precedentes, partirá de uma análise completa e criteriosa da legislação, dos precedentes e da história institucional como um movimento constante, assim como a leitura feita pela própria sociedade dos princípios jurídicos que se aplicam à situação e as suas convicções sobre os valores que circundam a situação, quando Hércules fixa direitos jurídicos, “já levou em consideração as tradições morais da comunidade, pelo menos do modo como estas são capturados no conjunto do registro institucional que é sua função interpretar." (DWORKIN, 2002, p. 196)

De acordo com Habermas:

O juiz Hércules dispõe de dois componentes de um saber ideal: ele conhece todos os princípios e objetivos válidos que são necessários para a justificação; ao mesmo tempo, ele tem uma visão completa sobre o tecido cerrado dos elementos do direito 
vigente que ele encontra diante de si, ligados através de fios argumentativos. Ambos os componentes traçam limites à construção da teoria. $\mathrm{O}$ espaço preenchido pela sobre-humana capacidade argumentativa de Hércules é definido, de um lado, pela possibilidade de variar a hierarquia dos princípios e objetivos e, de outro lado, pela necessidade de classificar criticamente a massa do direito positivo e de corrigir 'erros'. (HABERMAS, 2003, p. 263)

Ao decidir um caso difícil, Hércules sabe que os outros juízes decidiram casos que, apesar de não guardarem as mesmas características, tratam de situações afins. Deve, então, considerar as decisões históricas como parte de uma longa história que ele deve interpretar e continuar, de acordo com suas opiniões sobre o melhor andamento a ser dado à trama em questão.

Hércules deve se posicionar, formar sua própria opinião sobre o problema apresentado, assim como um romancista em cadeia deve encontrar alguma maneira coerente de ver um personagem e um tema, "tal que um autor hipotético com o mesmo ponto de vista pudesse ter escrito pelo menos a parte principal do romance até o momento em que lhe foi entregue.” (DWORKIN, 2003, p. 288)

Mas existe um limite para o uso das convicções do juiz ao decidir um caso, conforme demonstra Dworkin, Hércules não deve, em momento algum, fazer nenhuma escolha entre suas próprias convicções políticas e aquelas que ele considera como as convicções políticas do conjunto da comunidade. Ao contrário,

\footnotetext{
Sua teoria identifica uma concepção particular de moralidade comunitária como um fator decisivo para os problemas jurídicos; essa concepção sustenta que a moralidade comunitária é a moralidade política que as leis e as instituições da comunidade pressupõem. Ele deve, por certo, basear-se em seu próprio juízo para determinar que princípios de moralidade são estes, mas essa forma de apoio é a segunda daquelas que distinguimos, uma forma que é inevitável em algum nível. (DWORKIN, 2002, p. 197-198)
}

Hércules encontra-se norteado por princípios que o auxiliam na composição de uma teoria que explica e justifica a decisão como a única correta. Desta forma, compreende-se o porquê do nome Hércules, dada a grandeza do trabalho do juiz.

Mesmo quando nenhuma regra regula um caso a ser julgado, uma das partes pode, mesmo assim, ter o direito de ganhar a causa. Ao juiz cabe descobrir quais são os direitos das partes, que é preexistente à atividade jurídica. Quando Dworkin trata de direitos jurídicos, este concebe que quando um sujeito tem um direito, o juiz, ao decidir a controvérsia, toma a decisão favorável suportada pelo direito afirmado. 
A maneira que esta resposta correta será encontrada, depende de um exaustivo e criterioso processo de análise e comparação dessas fontes do direito como integridade, sem dúvida alguma, um trabalho de dimensões hercúleas.

A interpretação dada por Hércules a um caso difícil será sempre assentada sobre a moral, mesmo que a moral política; e a fonte da moralidade no direito como integridade está nos princípios. Hércules, com sua paciência sobre-humana, verifica cada hipótese jurídica que sua decisão acarreta, qual delas seria a decisão que melhor oferecesse uma adequada justificação para uma comunidade de princípios.

O direito como integridade pede que os juízes admitam, na medida do possível, que o direito é estruturado por um conjunto coerente de princípios sobre a justiça, a equiidade e o devido processo legal adjetivo, e pede-lhes que os apliquem nos novos casos que se lhes apresentem, de tal modo que a situação de cada pessoa seja justa e equiitativa segundo as mesmas normas. Esse estilo de deliberação judicial respeita a ambição que a integridade assume, a ambição de ser uma comunidade de princípios. (DWORKIN, 2003, p. 291)

Ao decidir um caso difícil, Hércules estaria, segundo o direito como integridade, obrigatoriamente vinculado a um compromisso de oferecer uma justificativa de acordo com a história legislativa, moral e política do contexto em que tal caso se assenta, assim como, demonstrar que sua decisão foi baseada em princípios e não em compromissos ou estratégias políticas.

Importa lembrar que os casos difíceis são aqueles que apresentam-se para qualquer juiz quando sua análise preliminar não fizer prevalecer uma entre duas ou mais opções de interpretação de uma lei, ele então deve fazer uma análise construtiva das interpretações possíveis, perguntando-se qual delas apresenta em sua melhor luz, do ponto de vista da moral política, a estrutura das instituições e decisões da comunidade, suas normas públicas como um todo. Sua decisão vai refletir não apenas suas opiniões sobre a justiça e a eqüidade, mas suas convicções de ordem superior sobre a possibilidade de acordo entre esses ideais quando competem entre si.

Dworkin desenvolve todos os exemplos de interpretação judicial baseado nos casos difíceis, e o justifica sustentando que Hércules não precisa de método para os casos difíceis e outro para os fáceis, pois nos casos fáceis as respostas às perguntas parecem óbvias, tanto que não se percebe se há uma teoria interpretativa em operação.

Dworkin supera, com a análise criteriosa de Hércules sobre os casos difíceis, a teoria da "vontade do legislador", que assegura a validade da aplicação de determinada norma jurídica na concepção positivista, se essa é reconhecidamente a intenção inicial do legislador 
que formulou tal regra. A teoria da intenção legislativa exige que "as leis devem ser interpretadas não de acordo com o que os juízes acreditam que iria torná-las melhores mas de acordo com o que pretendiam os legisladores que realmente a adotaram." (DWORKIN, 2003, p. 278)

O autor admite que na prática jurídica norte-americana os juízes freqüentemente recorrem às múltiplas declarações feitas por membros do Congresso e outros legisladores nos relatórios das comissões a respeito da finalidade de uma lei. Tais declarações formam uma "história legislativa" a que os juízes devem respeitar. Tal teoria:

Supõe que a legislação é uma ocasião ou um exemplo de comunicação, e que os juízes se voltam para a história legislativa quando uma lei não é clara, para descobrir qual era o estado de espírito que os legisladores tentaram comunicar através de seus votos. (DWORKIN, 2003, p. 379)

Dworkin apregoa que é impossível saber qual foi a intenção de um legislador ao votar uma lei há trezentos anos, e, mesmo se houvesse a possibilidade de saber exatamente qual foi a intenção deste legislador ao promulgar a lei, esta intenção seria incoerente com a situação contemporânea, e conseqüentemente, com a interpretação construtiva da tese dworkiniana.

Hércules [...] entende a idéia do propósito ou da intenção de uma lei não como uma combinação dos propósitos ou intenções de legisladores particulares, mas como o resultado da integridade, de adotar uma atitude interpretativa com relação aos eventos políticos que incluem a aprovação da lei. (DWORKIN, 2003, p. 380)

Dworkin sustenta que os métodos de Hércules oferecem uma interpretação melhor da verdadeira prática judicial, ele entende a idéia do propósito ou da intenção de uma lei não como uma combinação de intenções de legisladores particulares, mas como o resultado da integridade, de adotar uma atitude interpretativa com relação aos eventos políticos que incluem a aprovação da lei. "Ele anota as declarações que os legisladores fizeram no processo de aprová-la, mas trata-as como eventos políticos importantes em si próprios, não como evidência de qualquer estado de espírito por detrás delas.” (DWORKIN, 2003, p. 380)

Hércules deve então encontrar uma justificativa que se ajuste à lei que lhe pedem que aplique, que essa justificativa seja coerente com a legislação em vigor. Assim, deve buscar uma combinação de políticas, princípios, na busca do melhor exemplo para aquilo que os termos da lei claramente requerem. Sua interpretação deve refletir não apenas suas convicções sobre justiça, mas também seus ideais de integridade e eqüidade política, na medida em que esses se aplicam à legislação vigente em uma democracia. (DWORKIN, 2003, p. 405) 
Dworkin, ao buscar aplicar o ideal da integridade na Constituição, a diferencia da legislação ordinária, considerando-a como uma lei incomum, razão pela qual desenvolve uma aplicação diferenciada da estratégia de princípios. Segundo Dworkin, a Constituição é o fundamento para a criação de outras leis, e por esse motivo a interpretação dada por Hércules ao documento como um todo, bem como às suas cláusulas abstratas, deve ser também fundamental. Deve ajustar-se às disposições mais básicas do poder político da comunidade e ser capaz de justificá-las, o que significa que deve ser uma justificativa extraída dos aspectos mais filosóficos da teoria política. "Os juristas são sempre filósofos, pois a doutrina faz parte da análise de cada jurista sobre a natureza do direito, mesmo quando mecânica e de contornos pouco nítidos.” (DWORKIN, 2003, p. 454)

Hércules não é um historicista, tampouco tem o estilo aventureiro às vezes satirizado sob o epíteto de 'direito natural'. Ele não acha que a Constituição é apenas o que de melhor produziria a teoria da justiça e da eqüidade abstratas à guisa de teoria ideal. É guiado, em vez disso, por um senso de integridade constitucional. (DWORKIN, 2003, p. 474)

Os argumentos de Hércules abrangem a convicção popular e a tradição nacional sempre que estas forem pertinentes à questão da soberania: qual interpretação da história constitucional apresenta essa história geral em sua melhor luz. "Pela mesma razão, e com o mesmo objetivo, eles se baseiam em suas próprias convicções sobre justiça e eqüidade e na correta relação entre elas.” (DWORKIN, 2003, p. 474)

$\mathrm{O}$ autor em estudo comenta que a atividade judiciária sofre limitações institucionais, como as impostas pela supremacia legislativa e a do precedente estrito. Mesmo que Hércules esteja convencido de que estes padrões institucionais possuam erros, este deve respeitar estes institutos, por ser este um traço do direito como integridade.

Se Hércules houvesse decidido ignorar a supremacia legislativa e o precedente estrito sempre que a ignorância dessas doutrinas lhe permitisse aperfeiçoar a integridade do direito, considerada por si só, matéria relevante, então ele teria violado totalmente a integridade. Pois qualquer interpretação geral bem-sucedida de nossa prática legal deve reconhecer essas limitações institucionais. (DWORKIN, 2003, p. 479)

Hércules, o autor do romance em cadeia, não é um "semi-deus" qualquer, pois ele não pode ignorar a supremacia legislativa, nem a força gravitacional dos precedentes, apesar de possuir muitas outras capacidades, tais como, a capacidade de criar todo um sistema coerente em suas decisões do caso concreto, sempre de acordo com os princípios explícitos e implícitos da comunidade na qual ele atua. "Ele nunca será um tirano que impõe sua própria vontade em 
suas decisões, pois sempre aplicará os direitos previamente estabelecidos pela própria sociedade." (SOARES, 2006, p. 10-11)

Críticos acusam Dworkin de ser excessivamente abstrato na construção de seu modelo teórico, sustentando que um juiz de verdade tem muito menos tempo do que até um professor de direito, para construir suas decisões imitando Hércules.

Estes críticos sustentam que as prerrogativas de tempo e paciência ilimitados que Hércules possui são irreais, um juiz jamais disporia de tais vantagens. Além disso, Dworkin teria elevado a coerência a uma exigência infinita e a interpretação a uma temporalidade impossível que só pode ser cumprida pelas capacidades super-humanas de Hércules.

Frank Michelman sugere que:

\begin{abstract}
O que está faltando na concepção de direito de Ronald Dworkin como integridade (jurídica) [...] é diálogo. Hércules, o juiz mítico de Dworkin, evita outras pessoas. Ele é também excessivamente heróico. Suas construções narrativas são monólogos. Ele não conversa com ninguém, exceto através de livros. Ele não tem encontros. Ele não se reúne com ninguém. Nada o estremece. Nenhum interlocutor viola o isolamento inevitável de sua experiência e perspectiva. Mas, depois de tudo, Hércules é só um homem. Ele não é toda a comunidade. Nenhum homem ou mulher pode ser toda a comunidade. (MICHELMAN, 2006, p. 21)
\end{abstract}

Porém Dworkin faz um alerta em "O Império do Direito" de que é consciente de que a sua tese interpretativa e sua noção de integridade não se aplicam de maneira perfeita, admite que não seria possível reunir em um único e coerente sistema de princípios todas as normas e padrões exigidos pela integridade política, legal e legislativa. (DWORKIN, 2003, p. 261)

Mas o compromisso com a integridade nos leva a considerar isso como um defeito, onde temos Hércules e o ideal de integridade como uma meta a ser alcançada de forma a evoluir a atividade jurisdicional.

Dworkin admite que uma interpretação plena como a de Hércules é humanamente impossível, nenhum juiz poderia impor nada que de uma vez só pudesse abranger todo o direito de uma comunidade. Se um juiz real decidisse imitar Hércules nos menores detalhes, tentando em cada caso defender uma teoria do geral do direito, iria ver-se paralisado enquanto sua pauta de causas se tornaria cada vez mais sobrecarregada. "É por isso que imaginamos um juiz hercúleo, dotado de talentos sobre-humanos e com tempo infinito a seu dispor. Um juiz verdadeiro, porém só pode imitar Hércules até certo ponto”. (DWORKIN, 2003, p. 294)

Um juiz experiente terá um conhecimento suficiente do terreno em que se move seu problema e decide a maioria dos casos de maneira bem menos metódica, mas Hércules nos mostra a estrutura oculta de suas sentenças, deixando-as abertas ao estudo e à crítica. Ele o faz 
como o que os demais juízes fariam se tivessem toda uma carreira a dedicar a uma única questão; precisam não de uma concepção do direito diferente da dele, mas de algo que ele nunca precisou cultivar: eficiência e capacidade de administrar com prudência. (DWORKIN, 2003, p. 316)

Stephen Guest argumenta que:

\begin{abstract}
Hércules é um juiz ideal e então é inútil supor que ele realmente existe. Este ponto de vista é tão banal mas ainda é surpreendente como isso é criticado em Dworkin. [...] A idéia econômica de mercado perfeito é semelhantemente um ideal. Nós julgamos as imperfeições no mundo real pela referência daquele ideal sem sentir a necessidade de dizer que há mercados perfeitos no mundo real. Então porque deveríamos nos sentir incomodados que uma pessoa como Hércules não exista? ${ }^{8}$ (GUEST, 1997, p. 39, tradução nossa)
\end{abstract}

Para este autor, a dificuldade que os leitores têm com Hércules é devida ao fato de que o seu esquema de argumento legal é bem mais complexo do que, por exemplo, o fornecido pela regra de reconhecimento de Hart. Dworkin nem poderia fornecer um esquema de premissas de interpretação dedutiva simplesmente porque ele não pensa o Direito desta forma. Sua teoria critica esse ponto de vista formalista e positivista por ser, em sua opinião, simples demais. (GUEST, 1997, p. 39)

\title{
5 CONSIDERAÇÕES FINAIS
}

O objetivo deste trabalho foi o de analisar o processo interpretativo de Ronald Dworkin, de maneira que se compreenda o método que Dworkin propõe na interpretação das lides judiciais, de maneira que se possa oferecer a melhor luz às normas legais e princípios que regem o cenário jurídico de uma sociedade. Ainda, o método que o referido autor propõe para que se alcance uma decisão justa e legítima sem extrapolar os limites da atividade judiciária.

Com a pesquisa realizada foi possível compreender as etapas interpretativas que Dworkin propõe no seu método de interpretação construtiva, que oferecem uma maneira de identificação dos elementos a serem interpretados e uma melhor maneira de buscar a lei e os princípios que ofereçam a melhor decisão ao caso apresentado.

Embora o autor aqui em estudo use como parâmetro uma sociedade guiada pelo sistema da common law, a partir do momento que o Supremo Tribunal Federal brasileiro - em consequência da nova leitura principiológica da Constituição - começa a atuar não mais 
somente como aplicador mas também como realizador de direitos, ocorre uma combinação de tradições (direito romano germânico e common law).

Como citado anteriormente, esta combinação leva à decisões inovadoras, à conquista de direitos, mas também gera insegurança jurídica, o Poder Judiciário necessita de legitimação nas decisões tomadas. O processo interpretativo de Dworkin busca oferecer essa legitimação, pois oferece uma interpretação crítica e (re)construtiva do direito.

O processo interpretativo de Dworkin passa pela fase de identificação do fato jurídico, a adequação do fato às normas e princípios cabíveis para a solução da lide, e então segue a fase de justificação da decisão, a busca da melhor resposta ao caso apresentado. Dworkin sustenta que um juiz tem o dever legal de analisar de modo mais abrangente as fontes de lei, os princípios e a história jurídica da comunidade, de maneira que torne a atividade judiciária capaz de alcançar os casos mais difíceis e ofereça a melhor resposta à lide apresentada.

É inegável que os valores e princípios são fundamentais na teoria de Dworkin. Este defende que é de crucial importância que a atividade judiciária esteja norteada por princípios como (e principalmente) a integridade, que vai possibilitar uma adequação esclarecedora das práticas jurídicas de uma comunidade. Portanto as decisões tomadas nas cortes como, principalmente, o STF devem buscar a resposta mais coerente frente ao sistema de princípios consitucional.

No que tange à previsibilidade judicial, foi possível, através de exemplos como o do romance em cadeia, compreender a interpretação construtiva de Dworkin e a forma como este preza pela coerência nas decisões judiciais, proporcionando medidas capazes de se atingir uma adequação do Direito às transformações sociais sem que, com isso, haja um sacrifício absoluto do valor de previsibilidade das decisões judiciais.

Foi possível compreender porque a decisão judicial é tão importante e como isso pode influenciar não só sobre o direito das partes, mas em toda a história legal da comunidade e na formação de seu direito. Demonstra que o direito não é uma prática neutra e livre de valores, mas uma atividade construtiva, dinâmica, que não exclui os juízes do processo de criação do direito, pois estes constroem o quadro jurídico de uma comunidade através da busca nos princípios para a fundamentação das decisões.

Avaliou-se como o autor compreende os limites postos pelo sistema jurídico ao uso de juízos valorativos individuais do julgador, que em momento algum deve fazer uma escolha entre suas próprias convicções e aquelas que ele considera como as convicções da 
comunidade. A moralidade política comunitária deve prevalecer, de forma a se tomar a decisão que melhor corresponde ao ideal de integridade.

As obras de Dworkin são fontes inesgotáveis de referências para discussões acadêmicas, com inúmeras abordagens que são substanciais em nosso âmbito jurídico, na qual a busca de apenas um referente é insuficiente para demonstrar todo o aparato filosófico que Dworkin nos fornece em sua obra.

Dworkin possui uma ampla bibliografia com linguagem elegante e clara, porém carregadas de um raciocínio complexo e de uma profunda carga filosófica, que instiga o leitor a buscar argumentos que possam rebater suas teses e aperfeiçoar sua teoria.

Embora haja muitos detratores das idéias de Dworkin, é inegável que sua teoria desperta discussões que vão além dos limites que seus críticos desejariam. Dworkin é um fenômeno, um autor que convoca todos os profissionais de Direito a uma reflexão crítica da atividade judiciária. 


\section{REFERÊNCIAS}

AREAAS, Paulo André Morales. Um estudo comparativo entre a doutrina de Dworkin e a súmula de efeitos vinculantes - E. C. $n^{\circ}$ 45, Brasil, 2005. Revista da Faculdade de Direito de Campos. Ano VI, n 6 - junho, 2005.

CALSAMIGLIA, Albert. EI Concepto de Integridad en Dworkin. Doxa: Cuadernos de Filosofía del Derecho. Alicante: Biblioteca Virtual Miguel de Cervantes, 2001, núm. 12 (1992), p.155-176.

CHUEIRI, Vera Karam de; SAMPAIO, Joanna Maria de Araújo. Como levar o Supremo Tribunal Federal a sério: sobre a suspensão da tutela antecipada n. 91. Revista Direito GV, São Paulo, n. 9, p. 045-066, jan-jun 2009.

CHUEIRI, Vera Karam de. Filosofia do direito e modernidade: Dworkin e a possibilidade de um discurso instituinte de direitos. Curitiba: J. M, 1995.

CITTADINO, Gisele. Pluralismo, direito e justiça distributiva. 4. ed. Rio de Janeiro: Lumen Juris, 2009.

DWORKIN, Ronald. Levando os direitos a sério. Tradução e notas Nelson Boeira. São Paulo: Martins Fontes, 2002.

DWORKIN, Ronald. O Império do direito. Tradução de Jefferson Luiz Camargo. São Paulo: Martins Fontes, 2003.

DWORKIN, Ronald. Uma questão de princípio. Tradução de Luís Carlos Borges. 2 ed. São Paulo: Martins Fontes, 2005.

GUEST, Stephen. Ronald Dworkin. 2nd ed. Edinburgh: Edinburgh University Press, 1997.

GÜNTHER, Klaus. Teoria da argumentação no direito e na moral: justificação e aplicação. Tradução de Cláudio Molz. São Paulo: Landy Editora, 2004.

HABERMAS, Jürgen. Direito e democracia: entre a facticidade e a validade. Trad. Flávio Beno Siebeneichler. Rio de Janeiro: Tempo Brasileiro, 2003. v. I

HART, Herbert L.A. O Conceito de Direito. 4 ed. Tradução de A. Ribeiro Mendes. Lisboa: Fundação Caloustre Gulbenkian, 2005.

MARTINS, Argemiro Cardoso Moreira; FERRI, Caroline. O problema da discricionariedade em face da decisão judicial com base em princípios: a contribuição de Ronald Dworkin. Revista Novos Estudos Jurídicos, Itajaí: Universidade do Vale do Itajaí, v.11, n.2, jul-dez 2006.

MICHELMAN, Frank, 1985. apud DUTRA,Delmar José Volpato. A teoria discursiva da aplicação do direito: o modelo de habermas. Veritas. Porto Alegre. v. 51. n. 1. p. 18-41. Março, 2006. 
SGARBI, Adrian. Clássicos de Teoria do Direito. Rio de Janeiro: Lumen Juris, 2006.

SOARES, Natália Lourenço. Uma relação entre o tipo ideal de legislação de jeremy waldron e o juiz - modelo Hércules de Ronald Dworkin. In: XV Congresso Nacional do CONPEDI 2006, Manaus-AM. Anais do XV Congresso Nacional do CONPEDI. Manaus: COMPEDI, 2006.

VIANNA, Luiz Werneck (et al). A judicialização da política e das relações sociais no Brasil. Rio de Janeiro: Revan, 1999.

VIDAL, Isabel Lifante. La interpretación jurídica en la teoría del derecho contemporánea. Madrid: Centro de Estudios Políticos y Constitucionales, 1999b.

VIDAL, Isabel Lifante. La teoría de Ronald Dworkin: la reconstrucción del derecho a partir de casos. Jueces para la democracia, Madrid, N³6, p. 41-46, 1999a. 


\title{
NOTAS
}

\begin{abstract}
${ }^{1}$ Importa citar que a respeito do termo "teorias semânticas do direito", Isabel Lifante Vidal assim esclarece: Con la expressión 'teorías semánticas', Dworkin se refiere a aquellas teorías según las cuales el significado de la palabra de 'Derecho' viene dado por ciertas reglas de uso (semánticas) aceptadas por la comunidad lingüística, de modo que los juristas seguirían principios lingüísticos (aun de forma inconsciente) para juzgar las proposiciones acerca del Derecho.
\end{abstract}

2 Abandonar las teorías semánticas y optar por una perspectiva de análisis del Derecho diferente: una teoría que considere al Derecho como un concepto interpretativo.

${ }^{3}$ De maneira que la presencia de este consenso se convierte para Dworkin prácticamente en un elemento definitorio de las comunidades interpretativas.

${ }^{4}$ Abandono, reforma o introducción de algunas de las reglas identificadas en la primera etapa; esto coincide precisamente con el requisito del segundo elemento de la actitud interpretativa.

${ }^{5}$ El juez dworkiniano se debe situar precisamente en la etapa postinterpretativa y su tarea consiste en resolver los casos concretos através de la elaboración de la mejor teoría que reconstruya todo el sistema jurídico. Es em este sentido en el que puede decirse que Dworkin adopta una visión holística o integradora respecto al fenómeno jurídico.

${ }^{6}$ La teoría de Dworkin añade algo que no parece estar en teorías como la de Hart y que puede contribuir a la mejor comprensión del fenómeno jurídico: la ideia de 'coherencia', que es lo que permitiría ver al Derecho objetivo no como un mero conjunto de normas, sino como un conjunto de normas 'orientado' es decir, con ciertos objetivos. Este elemento parece incluso necesario para dar cuenta de las funciones que el proprio Hart atribuye al Derecho de guía de conducta de una determinada sociedad.

${ }^{7}$ A proper community, one in which it is fraternal association that provides the justification for political obligation, places weight on concern for well-being and equality. Dworkin calls such a community a 'community of principle' [...]. The community of principle, he says, makes the responsibilities of citizenship special because each citizen must respect the principles of fairness and justice that are embedded in the political arrangements in his particular community. The community of principle, therefore, provides a better defense of political legitimacy as well as a defense of our own political culture.

${ }^{8}$ Hercules is an ideal judge and so it is pointless to suppose that he really exists. This point is so banal but is surprising how common it is to criticize Dworkin on this ground. [...] The economist's idea of the perfect market is similarly such an ideal. We judge imperfections in the real world by reference to that ideal without feeling that there is any need to say that there are perfects markets in the real world. So why should we be bothered that no such person as Hercules exists? 